\title{
Non-viral Suicide Gene Therapy: Cytosine Deaminase Gene Directed by VEGF Promoter and 5-fluorocytosine as a Gene Directed Enzyme/prodrug System in Breast Cancer Model
}

\author{
Authors \\ Manouchehr Emamian¹, 2, Akbar Abbaspour², Tina Shahani1, 2, 4, Alireza Biglari¹, 4, Ali Sharafi², 3, 4
}

Affiliations

1 Department of Genetics \& Molecular Medicine, School of Medicine, Zanjan University of Medical Sciences, Zanjan, Iran

2 Cancer Gene Therapy Research Center, Zanjan University of Medical Sciences, Zanjan, Iran

3 Department of Pharmaceutical Biotechnology, School of Pharmacy, Zanjan University of Medical Sciences, Zanjan, Iran

4 Zanjan Pharmaceutical Biotechnology Research Center, Zanjan University of Medical Sciences, Zanjan, Iran

Key words

PAMAM dendrimer, Suicide gene therapy, Cytosine

deaminase, Gene delivery, VEGF promoter, 5-Fluorocytosine

received $\quad 31.03 .2021$

accepted 20.04.2021

published online 28.06 .2021

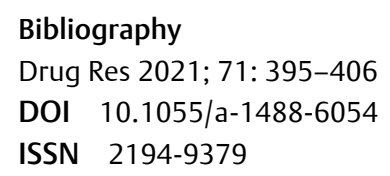

Dr. Ali sharafi

Cancer Gene Therapy Research Center

Zanjan University of Medical Sciences

Gavazang Street

45139-56184 Zanjan

Iran

Tel.: 00989359683974, Fax: 00982433473639

alisharafi@zums.ac.ir

\begin{abstract}
The present study investigated the potential of vascular endothelial growth factor (VEGF) promoter to derive cytosine deaminase ( $C D$ ) transfected by polyamidoamine (G4-PAMAM) dendrimers to 4T1 murine breast cancer cell line as gene-directed enzyme/prodrug therapy. The VEGF promoter and cytosine deaminase gene were cloned into the PEGFP-N1 vector from the genomic DNA of 4T1 and E. coli, respectively. The frequency of transfection for VEGF-CD-pEGFP-N1 and pEGFPN1- CD treated groups was $35 \pm 3$ and $36 \pm 4$, respectively. MTT assay was perform to evaluate the cytotoxic effects of converted 5 -flurocytosine on $4 \mathrm{~T} 1$ cells. Also, the optimal concentration of 5-FC in 4T1 cells transfected by VEGF-CD-pEGFP-N1 plasmid was evaluated. The GFP expression of transfected 4T1 cells by VEGF-CD-pEGFP-N1were observed by fluorescent microscopy and flowcytometry. Results demonstrated that the suicide CD gene was successfully expressed in 4T1 cells determined by RT-PCR and GFP expression. A concentration of $200 \mu \mathrm{g} / \mathrm{ml} 5$-FC was identified as optimal dose of prodrug. Furthermore, the $\mathrm{CD} / 5$-FC enzyme/prodrug system not only demonstrated toxicity on transformed 4T1 cells but also exerted a 'bystander effect' determined by MTT assay. The results showed that by $35 \%$ transfection with VEGF-CD-pEGFP-N1and CD-pEGFP-N1 plasmids, $80 \%$ and $90 \%$ inhibition of the cells growth occurred, respectively.
\end{abstract}

\section{Introduction}

Targeted therapy is a type of cancer treatment for precisely identify and attack the cancer cells. It can be used by itself or in combination with other treatments, such as standard chemotherapy, surgery or radiation therapy [1-3]. In recent years, several studies including molecular therapy, antiangiogenesis therapy [4], immunotherapy [5], apoptosis regulation [6], signal-transduction therapy [7], differentiation therapy [8], targeted radionuclide therapy [9] and gene therapy [10] are considered for targeted cancer therapy. Current gene therapy strategies for the treatment of tumors are restricted 
by the lack of targeting the malignant cells. One of the main problems for their in vivo applications is low transduction (or transfection) efficiency of the available gene transferring systems [11]. The cytotoxic systems convert a prodrug to an active drug intracellularly. Suicide gene therapy trials can be more promising than the other available gene therapy strategies [12]. The safety and effectiveness are the promising advantages of this approach for cancer treatment [13]. In the suicide gene therapy known as Gene-Directed Enzyme/Prodrug Therapy (GDEPT), the therapeutic transgenes have the ability to convert a non-toxic prodrug into cytotoxic drug or to express the toxic gene expression product [14-16]. Ideally, the gene should be expressed exclusively in the tumor cells not into the normal cells. The enzyme must reach a sufficient concentration for catalytic activity to activate the prodrug under physiological conditions for its clinical use. Because in vivo expression of the foreign enzymes will not occur in all cells of a targeted tumor, a bystander effect is required, whereby the prodrug is cleaved to an active drug that kills not only the tumor cells in which it is formed but also neighboring tumor cells that do not express the foreign enzyme [17].

Among many suicide genes, E. coli Cytosine Deaminase (CD) and Herpes Simplex Virus thymidine kinase (HSV-tk) are well documented for their strong therapeutic efficacy in cancer treatment [18]. In CD/5fluorocytosine (5-FC) system, a suicide gene, $C D$, catalyzes the conversion of the anti-fungal substrate 5-FC into 5-fluorouracil (5- FU), which is a lethal drug [19]. Suicide gene therapy, utilizing the $C D / 5-F C$ system, is an efficient approach for targeted therapy in cancer study [20-22]. Most suicide genes under investigation mediate sensitivity by encoding bacterial or fungal enzymes that convert inactive forms of a drug, into toxic metabolites capable of inhibiting nucleic acid synthesis [23, 24]. The cellular enzymes process the formulation to three cytotoxic antimetabolites: 1) 5-FdUTP, 2) 5-FUTP and 3) 5-FdUMP. The cytotoxic effects of $C D$ suicide therapy are based on three properties: a) formation of (5-FU) RNA, b) 5-FUDNA complexes and c) thymidylate synthase. The mitochondrial pathways are down-regulated through the control of $\mathrm{Bcl}-2$ [25]. Also, heat shock protein 90-beta is activated, contributing to tumor regression [26].

$\mathrm{CD} / 5$-FC system has some advantages over other GDEPT systems, including significant distant bystander effect independent of gap junctions $[27,28]$. One of the advantages of CD/5-FC system is radiosensitizing ability of 5 -FU to enhance tumor cytotoxicity efficiency along with radiotherapy $[25,29]$. Some studies have obtained the mutant forms of bacterial $C D$ in order to improve their kinetics including high affinity and lower $\mathrm{IC}_{50}$ for 5-FC [30].

The bystander effect can improve the therapeutic consequences which extended beyond the transfected tumor cells. There are currently five mechanisms investigated for the regression of untransfected cells due to bystander effects: a) release of soluble formulations, b) passage through gap junctions, c) passive transportation, d) stimulation of local microenvironment, and e) endocytosis of apoptotic vesicles. The CD/5-FU system demonstrates stronger local bystander effect than the other suicide genes. The 5 -FU diffuses efficiently within the tumor cells, and does not require cell to cell contact [25].

There are currently two main vehicles used to deliver the suicide genes: viral vectors and non-viral vectors [31]. Non-viral vectors are widely used with three different approaches: 1 ) naked DNA, 2) phys- ical methods and 3) chemical methods. Non-viral vectors such as cationic liposomes and cationic polymers are less efficient than viral vectors; they have the advantages of safety, simplicity of preparation and high gene encapsulation capability. These two delivery systems have a positive charge, which interacts with the negative charge of the DNA [32]. PolyAmidoAmine (PAMAM) dendrimers, is used for drug and gene delivery. The positive charge of PAMAM dendrimer surfaces decreases their cytotoxicity and has interesting implications for DNA transfection applications. Depending on its characteristics, such as a high efficiency in delivery, the capabilities of specific targeting, biodegradability, non-toxicity, non-immunogenicity, and capability of limiting DNA degradation, PAMAM dendrimer provides a promising approach for gene delivery [11,12].

Gene therapy for cancer requires vectors that are selectively expressed in tumor cells. It is achieved by putting the suicide gene under the control of a tumor specific promoter [33]. A wide number of cancer tissue specific promoters' studies have used tissuespecific promoter elements, such as: human telomerase reverse transcriptase (hTERT) promoter, carcino-embryonic antigen (CEA) promoter, and osteocalcin (OC) promoter [34]. In the recent years, various new promising promoters like auxin response factors (ARF) [35], glucose-regulated protein (GRP78) [36], chemokine (C-X-C motif) receptor-4 (CXCR4) [37], and osteopontin (OPN) [38], have been developed. The human cytomegalovirus (HCMV) promoter/ enhancer is a flexible promoter that is expressed in many cell types and provides high levels of trans-gene expression [39]. Based on the overexpression of the vascular endothelial growth factor (VEGF) in breast cancer cells $[34,40]$, a recombinant pEGFPN1 harboring the VEGF promoter and the CD suicide gene (pEGFPN1-VEGFp-CD), was constructed in the present study, for expression in 4T1 cell line. Plasmid constructs modified with the VEGF promoter element may provide improvements in gene expression for cancer cells. In the present study, we designed a tumor-specific promoter system by combining VEGF promoter, which can target to cancer cells with sufficient transcriptional activity. A gene-directed enzyme prodrug therapy (GDEPT) system consisting of the bacterial cytosine deaminase gene (bCD) driven by the VEGF promoter and the prodrug 5 -folourosytosine (5FC) was developed and its cytotoxicity effect was evaluated.

\section{Materials and Methods}

\section{Cell culture condition, reagents and instruments}

4T1 cells, E. coli BL21 and E. coli TOP10, were obtained from Pasteur institute of Iran and were cultured in LB agar media. 4T1 cells were cultured in RPMI 1640 medium, supplemented with $10 \%$ fetal bovine serum and $\% 1$ penicillin/streptomycin, and incubated at $37^{\circ} \mathrm{C}$ in a $5 \% \mathrm{CO}_{2}$ incubator.

The restriction enzymes were purchased from Takara Bio, Inc., (Otsu, Japan). T4 DNA ligase, Probest DNA polymerase and were purchased from New England Biolabs, Inc., (Ipswich, MA, USA). Agarose gel DNA extraction kit, 5-flurocytosine (5-FC), MTT and dimethyl sulfoxide (DMSO) were purchased from Sigma-Aldrich (Merck KGaA, Darmstadt, Germany).

The instruments that were used in the present study were: DLS (zetasizer, USA), ELISA Infinite Tecan (USA), Bio-Rad GenePCR 
(PerkinElmer, Inc., Waltham, MA, USA), OLYMPUS Ix53 optical microscope (Olympus Corporation, Tokyo, Japan), an OLYMPUS BX61 inverted fluorescence microscope and camera system (Olympus Corporation), BD Calibur Flow Cytometer (BD FACS Calibur, San Jose, CA, USA) and step -one-plus Real time PCR (ABI, USA).

\section{Molecular cloning of shuttle vector constructions}

Amplification of CD gene

E. coli strain BL21 was inoculated into $5 \mathrm{~mL}$ liquid LB medium with shaking, for overnight at $37^{\circ} \mathrm{C}$. The genomic DNA of E. coli BL21 was extracted by lysis method. It used as the template DNA for the amplification of CD gene by PCR. Specific primers of CD gene were designed based on published sequence (Genebank, NC-000913). The CD gene was amplified from the obtained genomic DNA of E. coli BL21 by PCR. The following primers were used: forward primer, 5'- TATAAGCTTGTGTCGAATAACGCTTTAC -3' (Italic part indicates the recognizing site of Hind III) and the reverse primer, 5' - ATTAAGCTTTCAACGTTTCTAATCGATGG -3' (Italic part indicates the recognizing site of HindIII). The PCR product of CD (1302 bp) and the expression vector, VEGF-pEGFP-N1 (5349 bp) made in our previous stud [41], were digested by HindIII and then ligated to obtain the final plasmid, VEGF-CD-pEGFP-N1 (6650bp). Also, the pEGFP-N1 plasmid was linearized by EcoRI and Xhol and the $\mathrm{CD}$ gene was inserted in its multiple cloning sites (HindIII). Finally, the recombinant plasmids sequences were verified by DNA sequencing, and the plasmid was further amplified and purified by a QIAfilter ${ }^{\mathrm{TM}}$ plasmid maxi kit (Qiagen China Co., Ltd., Shanghai, China), according to the manufacturer's protocol.

\section{Optimization of dendriplex transfection}

Preparation of PAMAM/DNA Dendriplex

G4-PAMAM-D, Sigma-Alderich, (USA), was kindly provided by Dr. Behzad Baradarn (Tabriz University of Medical Sciences, Tabriz, Iran). Dendriplexes of DNA/PAMAM complexes were prepared at different N/P ratios. The N/P ratios were calculated based on PAMAM nitrogen per nucleic acid phosphate. $2 \mu \mathrm{g}$ of DNA were mixed in HEPES buffer saline ( $20 \mathrm{mM})$ and appropriate amounts of diluted PAMAM by HEPES buffer saline were added to DNA solutions. Solutions were mixed. The resulting dendriplexes were incubated for $30 \mathrm{~min}$ at room temperature before use.

\section{Gel retardation assay}

Gel retardation assay was performed to assess the formation of electrostatic complexes between PAMAM and plasmid DNA. Briefly, a $0.1 \%$ agarose gel was prepared in TAE buffer $(1 X)$ with $0.5 \mu \mathrm{g} /$ $\mathrm{ml}$ safe stain. Dendriplexes were loaded into the agarose gel wells at $N / P$ ratios of $5,10,20,40,80$, and 160 . Samples of dendriplexes were run against free plasmid. Electrophoresis was conducted at 80 v for 45 min. Gel were photographed under UV light.

\section{Size and zeta potential measurements}

$20 \mu \mathrm{g}$ DNA was incorporated with the different amount of PAMAM in $10 \mathrm{~mL}$ HEPES buffer saline $(20 \mathrm{mM})$ giving $\mathrm{N} / \mathrm{P}=10,20,40,80$ and 160 polyplex. Dynamic light scattering was used to measure the mean diameters and surface Zeta potentials of the polyplexes using Zetasizer-Nano ZS (Malvern Instruments, Worcestershire, UK). The mean diameters and Zeta potentials of the dendriplexes were measured three times in triplicate.

\section{Cell culture and cytotoxicity assay of dendriplexes \& prodrug on 4T1 cells}

4T1 (murine mammary gland tumor), were cultured in RPMI 1640 medium with $10 \%$ fetal bovine serum (FBS), and were maintained at $37^{\circ} \mathrm{C}$ in a $5 \% \mathrm{CO} 2$ incubator. The potential PAMAM-G4 dendriplex cytotoxicity was evaluated on $4 \mathrm{~T} 1$ cells. This study was carried out by MTT assay of cell, according to the method described by Mosmann [42]. Briefly $5 \times 10^{4}$ cells were seeded in a 24 well plate and after $24 \mathrm{~h}$ the cells were treated with different N/P ratios of dendriplex at $500 \mu \mathrm{RPMI} 1640$ media. After incubation at $37^{\circ} \mathrm{C}$ for 4-6 $\mathrm{h}$, the growth medium was replaced with fresh FBS + /antibiotics + media and cultured for one day. The culture medium was then removed and a total of $20 \mu \mathrm{MTT}(5 \mathrm{mg} / \mathrm{ml})$ was added to each well and incubated for $4 \mathrm{~h}$ at $37^{\circ} \mathrm{C}$. The culture medium was then removed, followed by the addition of $100 \mu \mathrm{l}$ DMSO to each well. The absorbance was measured by a plate reader at $570 \mathrm{~nm}$. The cell viability percentages of different N/P ratios were calculated by considering the absorbance of control as $100 \%$ viability. Presented results correspond to $n=3$ performed in triplicate and expressed as mean \pm SD.

MTT colorimetric assay was used to evaluate the lethal effect and optimal concentration of 5FC on 4T1 and transfected 4T1 cells. Cells were cultured in 96-well plates $\left(1 \times 10^{4}\right.$ cells $)$ in $200 \mu \mathrm{l} \mathrm{RPMI}$ 1640. After $24 \mathrm{~h}$ of culture, the concentration of 5-FC was tested at $0,50,100,200,400,600,800$ or $1000 \mu \mathrm{M}$. The blank control, experimental and control groups were set up in five replicate groups. In total, 24,48 and $72 \mathrm{~h}$ after 5-FC treatment, the cell viability was determined using the MTT assay. The culture medium was then removed and a $20 \mu \mathrm{MTT}(5 \mathrm{mg} / \mathrm{ml})$ was added to each well and incubated for $4 \mathrm{~h}$ at $37^{\circ} \mathrm{C}$. The culture medium was then removed, followed by the addition of $100 \mu$ LMSO to each well. The absorbance (optical density; OD) of each well was measured at a wavelength of $570 \mathrm{~nm}$. The cell survival rate (\%) was calculated according to the following formula: (Experimental group OD value/blank control group OD value) $\times 100$. The $I_{50}$ value was determined with a Prism 3.03 program for each group.

\section{Cell transfection}

One day before transfection, cells were seeded in 6-well plates and cultured in growth medium without antibiotics. The cell confluency was approximately $70 \%$ at the time of transfection. $2 \mu \mathrm{g}$ plasmid per well was used for transfection in 6-well plate. PAMAM and plasmid DNA ( $p D N A$ ) were freshly diluted to equal volumes with HEPES buffer saline prior to use. The dendriplexes were prepared by adding PAMAM into pDNA using different N/P ratios. The dendriplexes were incubated for 30 minutes at RT. Based on standard PAMAM mediated transfection, the growth medium was replaced by fresh FBS free/antibiotics free medium ( $2 \mathrm{~mL}$ for 6 -well) and then the dendriplexes diluted by RPMI 1640 medium and added to the culture. After incubation at $37^{\circ} \mathrm{C}$ for $4-6 \mathrm{~h}$, the growth medium was replaced with fresh FBS + /antibiotics + media and cultured for one to two days for detection.

\section{CD and GFP gene expression analysis}

Fluorescent microscopy

To qualitatively evaluation of the transfection efficiency, cells transfected with pEGFP-N1 were observed and imaged using an invert- 
ed fluorescent microscope (Olympus BX61) for GFP expression at days 1 and 2 after transfection. After $72 \mathrm{~h}$ of cell culture $\left(37^{\circ} \mathrm{C}\right)$, cells were washed with PBS three times, trypsinized and collected for observing by fluorescence microscope. Cells were then centrifuged at $250 \times \mathrm{g}$ for $2 \mathrm{~min}$, washed with $4^{\circ} \mathrm{C}$ precooled PBS twice, fixed in $4{ }^{\circ} \mathrm{C}$ precooled $3 \%$ glutaraldehyde for $4 \mathrm{~h}$ and rinsed with PBS for $10 \mathrm{~min}$. Subsequently, they were fixed on slides at room temperature and observed under the fluorescent microscope.

Flow cytometry analysis

The transfection efficiency was quantitatively analyzed at cellular level by detecting and comparing the GFP excitation in the transfected and non-transfected cells. 2 days after transfection, the cell colonies were dissociated with trypsin and subjected to flowcytometry analysis (BD Biosciences, San Jose, CA, USA). The data were processed using FlowJo vX10 software. The transfection efficiency was determined as the percentage of viable GFP-positive cells among total cells.

\section{Real Time PCR}

After $48 \mathrm{~h}$ of transfection, total RNA was extracted from transfected $4 \mathrm{~T}_{1 C D}{ }^{+}$(CD-transfected 4T1), with TRIzol reagent (Invitrogen; Thermo Fisher Scientific, Inc.) and then one-step reverse transcription (RT)-PCR was performed using a One-step RT-PCR kit, according to the manufacturer's protocol. The forward (5' CAGCGGCTACCGTGAT-TCA 3') and reverse (5' TTTGCACATGGCGTTGG 3') primers were designed to amplify a $61 \mathrm{bp}$ fragment of the $C D$ gene. PCR reaction conditions were as follows: $95^{\circ} \mathrm{C}$ for $5 \mathrm{~min}$, followed by 30 cycles of $94^{\circ} \mathrm{C}$ for $30 \mathrm{sec}, 58^{\circ} \mathrm{C}$ for $30 \mathrm{sec}, 72^{\circ} \mathrm{C}$ for $1 \mathrm{~min}$, then $72^{\circ} \mathrm{C}$ for $10 \mathrm{~min}$. Differences in gene expression were normalized to the $\beta$-actin gene expression with the following primers: forward 5 '-aacgagcggttccgatgccctgag-3'; reverse 5'-tgtcgccttcaccgttccagtt3.

\section{Bystander effect}

After determining the percentage of transfection, the transfected cells were mixed with a certain amount of non-transfused cell and the normalized cells were seeded in 96-well plates 2 days prior prodrug addition. In brief, cells were washed with RPMI1640 and treated by 5-FC. The number of viable cells after 5-FC was measured according to the cell cytotoxicity assay mentioned in MTT assay section $[43,44]$.

\section{Evaluation of the effect of cell soup obtained from transfected cells on non-transfected cells}

According to the transfection instructions, cells in the 6-cell plate were transfected at N/P ratio $160.48 \mathrm{~h}$ after transfection, the supernatant of the transfected cells was collected. $66 \%$ and $33 \%$ of the cell soup were prepared and the cells were treated with 5-FC for 48 hours. Non-treated cells transfected with cell soup were considered as positive control and non-transfected cells untreated with cell soup were considered as negative control.

\section{Statistical analysis}

Statistical analyses were performed using GraphPad Prism 8.02 (C1992-2019 GraphPad Software, Inc.). Data were expressed as mean \pm standard deviation of the mean and analyzed by one-way ANOVA. The means were compared using Duncan's multiple range tests.

\section{Results}

\section{Construction and confirmation of the plasmids}

We used in Silico Snap Gene design to obtain the schematic structure of plasmids and MCS sites ( $\triangleright$ Fig. 1).

\section{VEGF- CD -pEGFP-N1 plasmid}

The CD gene was amplified from E. coli BL21 genomic DNA by PCR ( $\triangleright$ Fig. 2a). The VEGF-pEGFP-N1 vector and CD gene (1302 bp) were digested by HindIII restriction enzyme, before ligation and transformation into competent cell ( $\triangleright$ Fig. $2 \mathbf{b}$ ). Colony PCR was performed for transformation screening [41] ( $\triangleright$ Fig. 3a). The recombinant plasmid was extracted and verified by enzymatic digestion ( Fig. 3b).

\section{CD -pEGFP-N1 plasmid}

The $C D$ gene was amplified from E. coli BL21 genomic as mentioned before ( $\vee$ Fig. 2a). The pEGFP-N1 and a 1302 bp fragment of CD sequence were digested, before ligation and transformation into competent cell ( $>$ Fig. 4a). Colony PCR was performed for transformation screening ( $\triangleright$ Fig. 4b). The recombinant plasmid was extracted and verified by enzymatic digestion ( $\triangleright \mathbf{F i g} . \mathbf{4 c}$ ).

\section{Gel Retardation assay}

Gel retardation assay was performed to determine the most appropriate N/P ratio of dendrimer and plasmid DNA. PAMAM / plasmid complexes were prepared at various N/P ratios ranging from 5,10 , $20,40,80$ and 160 . After 30 min of incubation and dendriplex formation, the samples were electrophoresed ( $\vee$ Fig. 5).

\section{Transfection optimization}

In order to increasing the transfection efficiency, four factors including size, zeta potential, cell cytotoxicity and N/P ratio of dendriplex were investigated. As the N/P ratio increases, the particle size and the zeta potential of dendriplex and also the transfection percentage increase but the cell viability decreases ( $\triangleright$ Fig. 6).

\section{Dendriplexes size and zeta potential}

Since PAMAM has a positive charge and DNA has a negative charge in aqueous solution, PAMAM and DNA can form a complex with electrostatic effects in physiological conditions. PAMAM/plasmid complexes (dendriplex) at a most appropriate charge ratio were incubated for transfection of DNA. The particle size, size distribution and particle charge of PAMAM G4 dendrimer was measured by DLS (Zetasizer Nano ZS, Malvern Instruments, UK) ( Fig. 6). Data are expressed as mean \pm SD. In the following, size and charge of polyplex (DNA + PAMAM) with various N/P ratios were measured by DLS.

\section{Cellular cytotoxicity and transfection efficiency of dendriplex}

Increasing the dendrimer content of the dendriplex increases its cytotoxicity, but more importantly, increasing the size of the dendriplex may make endocytosis by cells almost impossible. As shown in $>$ Fig. 6a, with increasing the dendrimer content of the dendriplex, its size also increases, so that in the dendriplex with a N/P ratio of 160 , dendriplex size has reached to $400 \mathrm{~nm}$. 


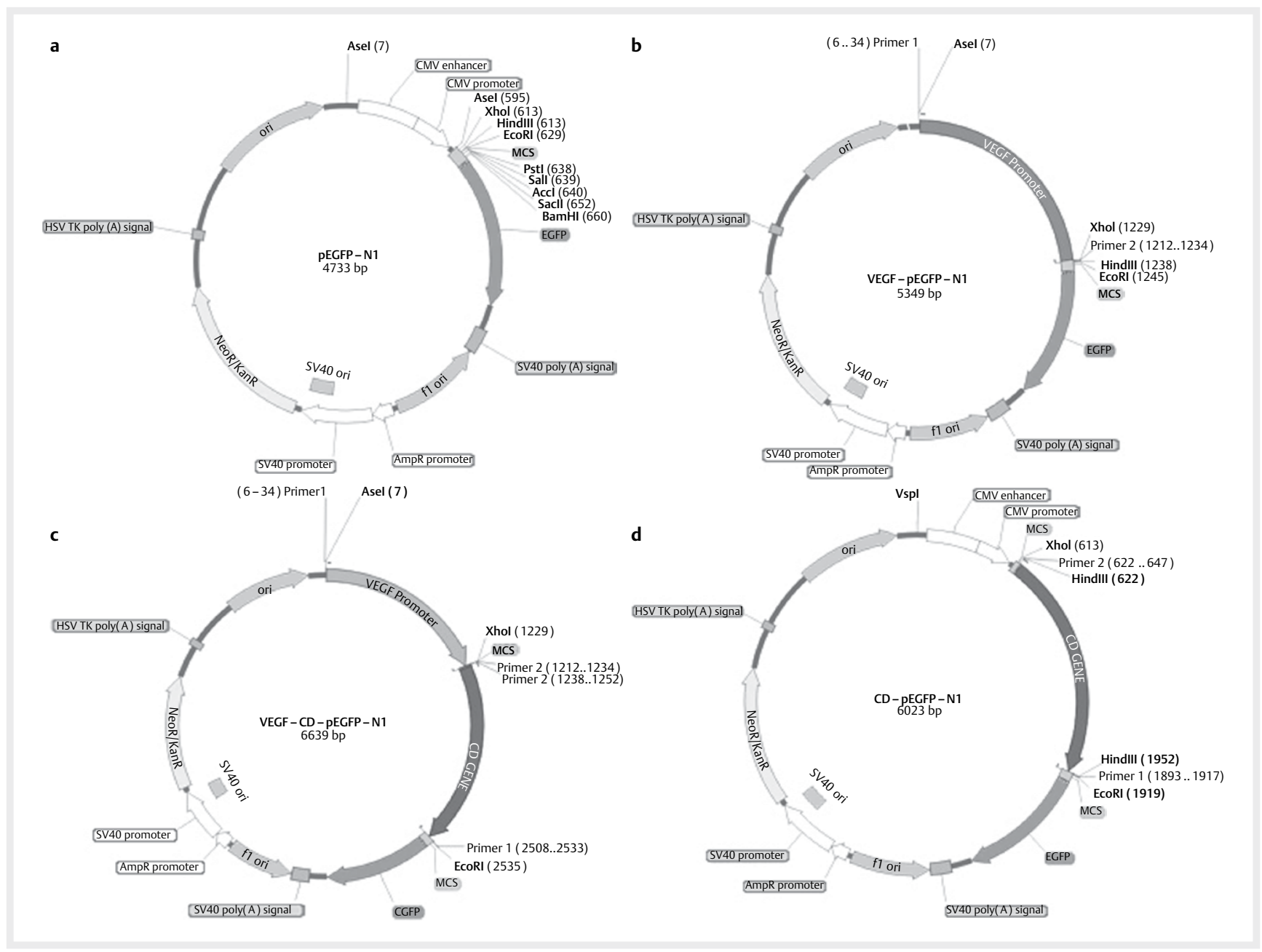

- Fig. 1 In Silico SnapGene constructs : a native pEGFP-N1 (with CMV promoter and total size 4733 bp), b VEGF-pEGFP-N1- (substitute VEGF with CMV, size : 5349 bp), c VEGF-CD-pEGFP-N1-, final construct, size : 6639 bp ), d CD-pEGFP-N1- ( size : 6023 bp).

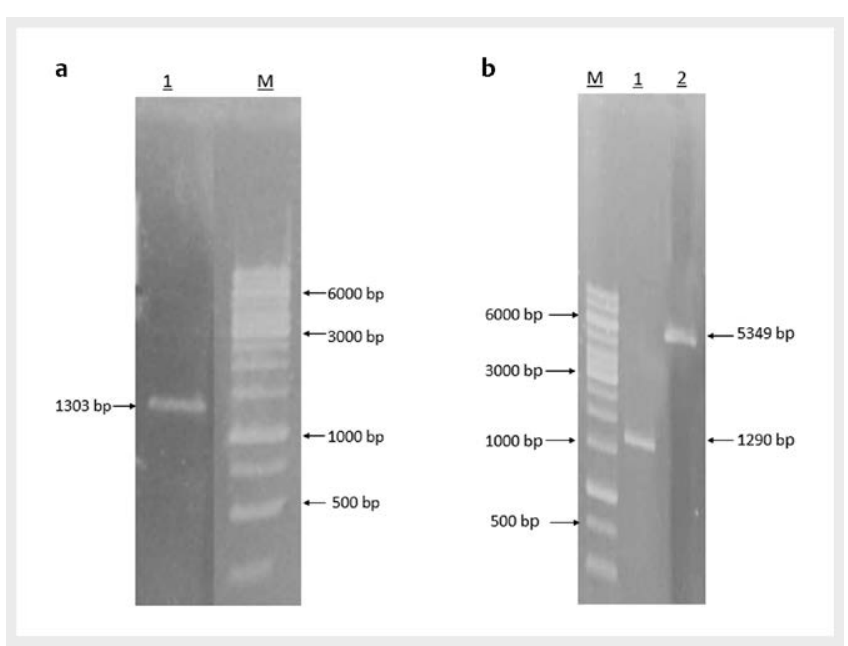

- Fig. 2 a) Gel electrophoresis of PCR product of $C D$ gene; $M: 1 \mathrm{~Kb}$ Ladder (Fermemtas Co.), 1: CD PCR product. b Gel electrophoresis of CD \& pEGFPN1-VEGF enzymayic digestion by HindIII), M: 1 Kb Ladder (Fermemtas Co.), lane1: cytosine deaminase, lane 2: VEGF- pEGFP-N1.

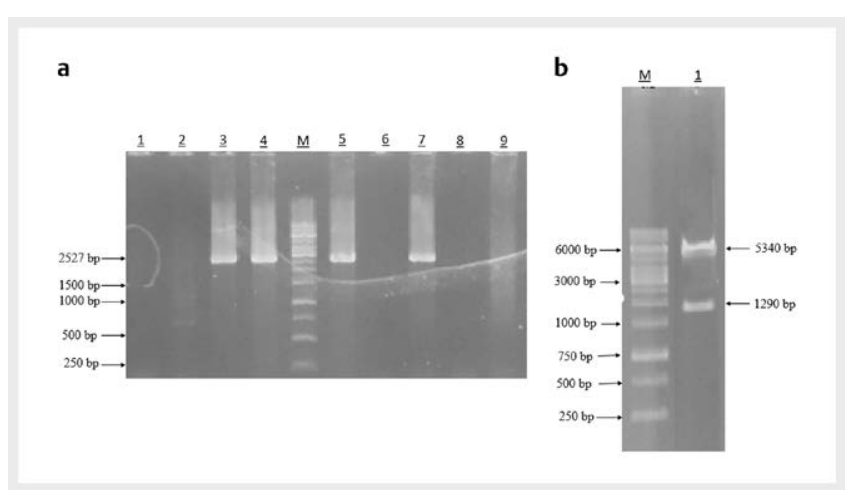

- Fig. 3 a): Gel electrophoresis of colony PCR products after ligation and transformation, lane M, 1 Kb ladder (Fermentas Co.), lanes 1 to 12 , colony PCR products of random selected colonies. Clones of 2 , 5,6,7,9 and 12 are positive transformed clones. b): Molecular confirmation of correct orientation of inserted CD into VEGF- pEGFP-N1 by enzymatic digestion by Xhol, Hindlll and electrophoresis: lane M: 1 Kb ladder (Fermentas Co.), lane1: uncut construct, lane 2: cut VEGFPEGFP-N1 (5349 bp) and CD (1300 bp). 


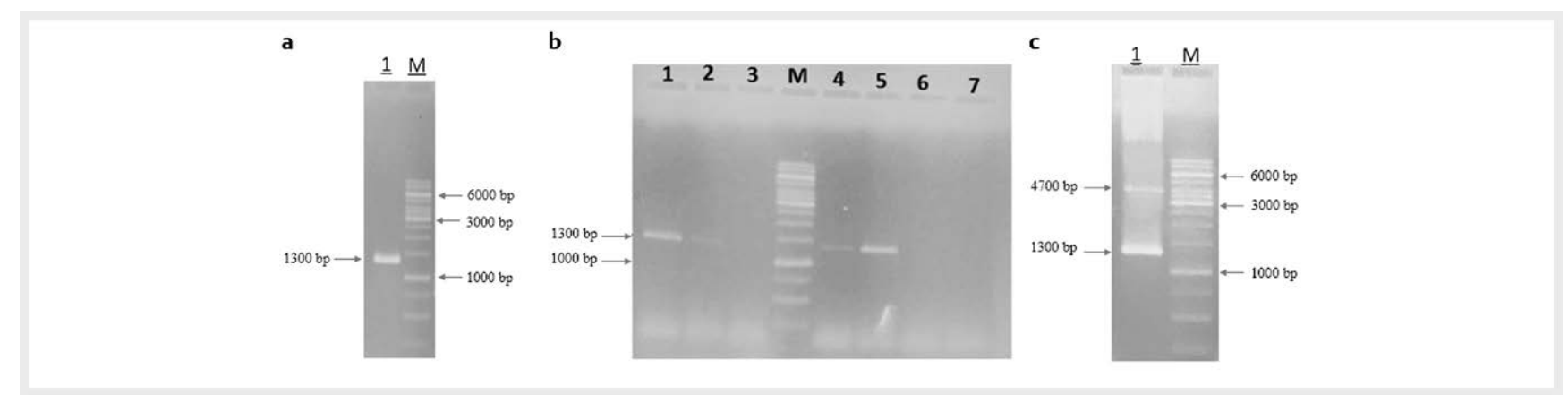

- Fig. 4 a Gel electrophoresis of PCR product of CD gene; M: 1 Kb Ladder (Fermemtas Co.), 1 CD PCR product. b Gel electrophoresis of colony PCR products after ligation and transformation, lane M, $1 \mathrm{~Kb}$ ladder (Fermentas $\mathrm{Co}$.), lanes 1 to 7 , colony PCR products of random selected colonies. Clones of 1, 4 and 5 are positive transformed clones. $c$ Molecular confirmation of inserted CD into VEGF- pEGFP-N1 by enzymatic digestion and electrophoresis: lane M: 1 Kb ladder (Fermentas Co), lane1: cut CD- pEGFP-N1 (4733bp) and CD (1302 bp).

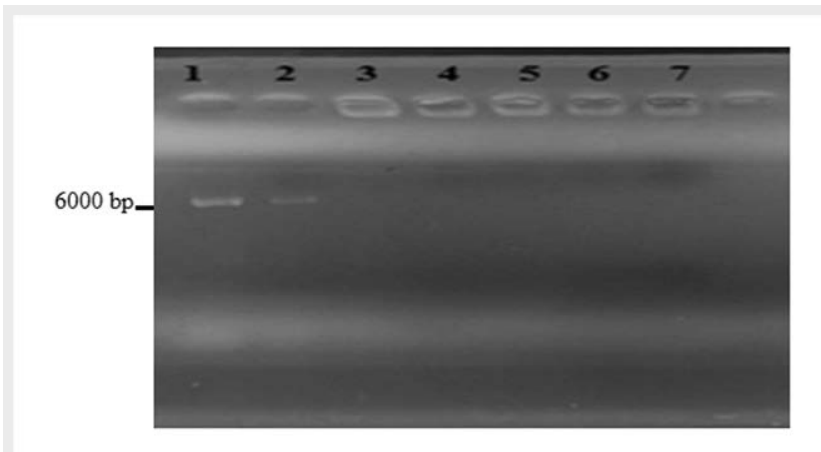

Fig. 5 Dendriplex Gel Retardation assay: Lane 1: control (pEGFPN1); lanes of 2 to 7: dendriplex (pEGFP-N1 + PAMAM) with different $\mathrm{N} / \mathrm{P}$ ratios $(5,10,20,40,80,160)$.

\section{Fluorescence microscope and flowcytometry analysis}

The constructs expresses a fluorescent reporter (green fluorescent protein) and a suicide cytosine deaminase gene, under control of VEGF promoter. The GFP expression was detected in 4T1 cells at different N/P ratios of dendriplexes ( $>$ Fig. 7). These show that dendriplexes were not cytotoxic in 4T1 tumor cells and were uptaken by these cells. The increasing N/P ratio may be influencing the total number of cells was GFP positive and the transfection efficiency. This hypothesis has been demonstrated qualitatively and quantitatively by fluorescent microscopy ( $\triangleright$ Fig. 7) and flowcytometry ( Fig. 8), respectively.

\section{Expression of CD driven by the VEGF promoter or CMV promoter inhibits 4T1 cells growth}

To investigate the level of cell proliferation in these enzyme/prodrug systems (VEGF-pEGFP-N1, VEGF-CD-pEGFP-N1 and CD-pEGFP$N 1), 4 T 1$ cells were transfected with these recombinant plasmids and its sensitivity to the 5 -FC was evaluated by MTT assay. Cell viability \% versus 5-FC was drowned using GraphPad Prism from the dose-cell viability curves. From the $\mathrm{IC}_{50}$ comparisons shown in - Fig. 9, it is clear that the cell growth inhibition rates in the VEGFCD-pEGFP-N1 and CD-pEGFP-N1 treated cell groups was observed while the cytotoxicity in the VEGF-pEGFP-N1 treated group was observed under the same experimental conditions. Cell growth inhibition rates were progressively elevated, may be due to 'bystander effect'. Therefore, the presence of bystander effect was investigated in the next experiment.

\section{Bystander effect}

For investigation of the bystander effect of each group in response to 5-FC treatment, co-cultures consisting of transfected and nontransfected $4 \mathrm{~T} 1$ cells were used. First, transfection efficiency was measured by flowcytometry and normalized cell transfection \% was prepared by co-culturing of transfected and non-transfected 4T1 cells for each group of 4T1 cells. All of cell groups was treated by $100 \mu \mathrm{M} 5-\mathrm{FC}$, and cell survival rates were calculated. Frequency of transfection for VEGF-CD-pEGFP-N1 and pEGFP-N1-CD treated group cells was $35 \pm 3$ and $36 \pm 4$ ( $\triangleright$ Fig. 10). By increasing in the transfection rates of VEGF-CD- pEGFP-N1 and CD - pEGFPN1 treated group cells, cell viability \% were progressively decreased, may be due to 'bystander effect'. However, the most prominent 'bystander effect' was observed in the CD-pEGFP-N1 treated groups.

\section{Effect of transfected cell supernatant on non- transfected cells}

To determine the effect of cell supernatant of transfected cells on prodrug, concentrations of $33 \%$ and $66 \%$ of cell supernatant were added on non-transfected cells and treated with different concentrations of prodrug. Toxicity in cells treated with cell supernatant was confirmed ( $\triangleright$ Fig. 11).

\section{RT-PCR of CD gene expression into transfected $4 T 1$ cell}

We used RT-PCR to detect the expression of the CD gene 1300-bp fragment and expression rate comparison between of VEGF-CDpEGFP-N1 and CD - pEGFPN1 treated group cells. The transcriptional activity of the CMV promoter (positive control) in each cell line was considered as $100 \%$. The expression of CD gene by the VEGF promoter was approximately from 36 to $72 \%$ of positive control (CD - pEGFP-N1) (॰ Fig. 12). 


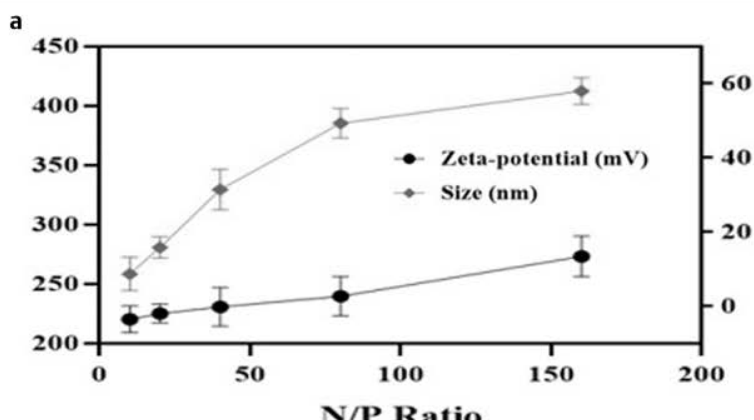

b

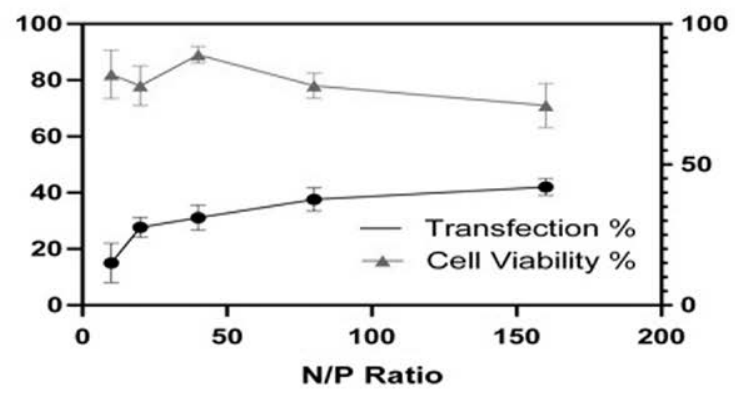

Size (d.nm): $\quad$ \% intensity: $\quad$ st Dev (d.n...

$\begin{array}{rllll}\text { Z-Average (d.nm): } 395.5 & \text { Peak 1: } & 410.5 & 89.2 & 118.1 \\ \text { Pdi: } 0.423 & \text { Peak 2: } & 109.3 & 10.8 & 20.35 \\ \text { Intercept: } 0.917 & \text { Peak 3: } & 0.000 & 0.0 & 0.000\end{array}$

Result quality: Good

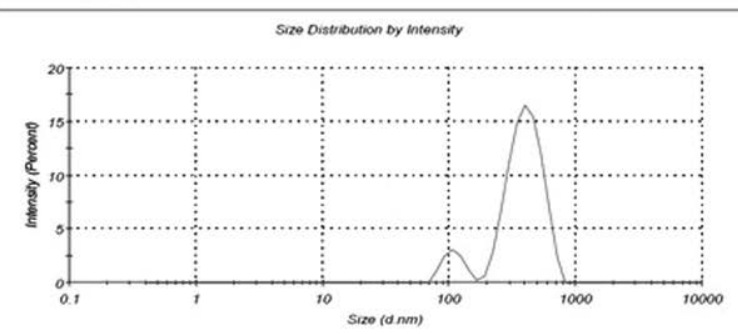

d

\begin{tabular}{|c|c|c|c|c|c|}
\hline Zeta Potential $(\mathrm{mV})$ : & 13.5 & Peak 1: & 12.3 & 97.4 & 5.50 \\
\hline Zeta Deviation $(\mathrm{mV})$ : & 9.23 & Peak 2: & 59.3 & 2.6 & 1.97 \\
\hline onductivity $(\mathrm{mS} / \mathrm{cm})$ : & 0.148 & Peak 3: & 0.00 & 0.0 & 0.00 \\
\hline Result quality : & Good & & & & \\
\hline
\end{tabular}

Zeta Potential Oistribution

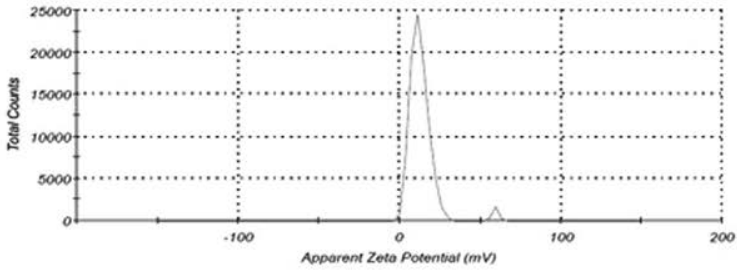

Record 71 inp1601

- Fig. 6 Characterization of the PAMAM /pEGFP-N1 (dendriplex). a Mean diameter and surface charge of the polyplex versus various N/P ratios using DLS (data expressed as mean + S.D. of three-independent measurements). b cellular cytotoxicity and transfection efficiency of dendriplex versus various N/P ratios; $\boldsymbol{c}$ and $\mathbf{d}$ Polyplex sizes and zeta potentials measured by Zetasizer for example.
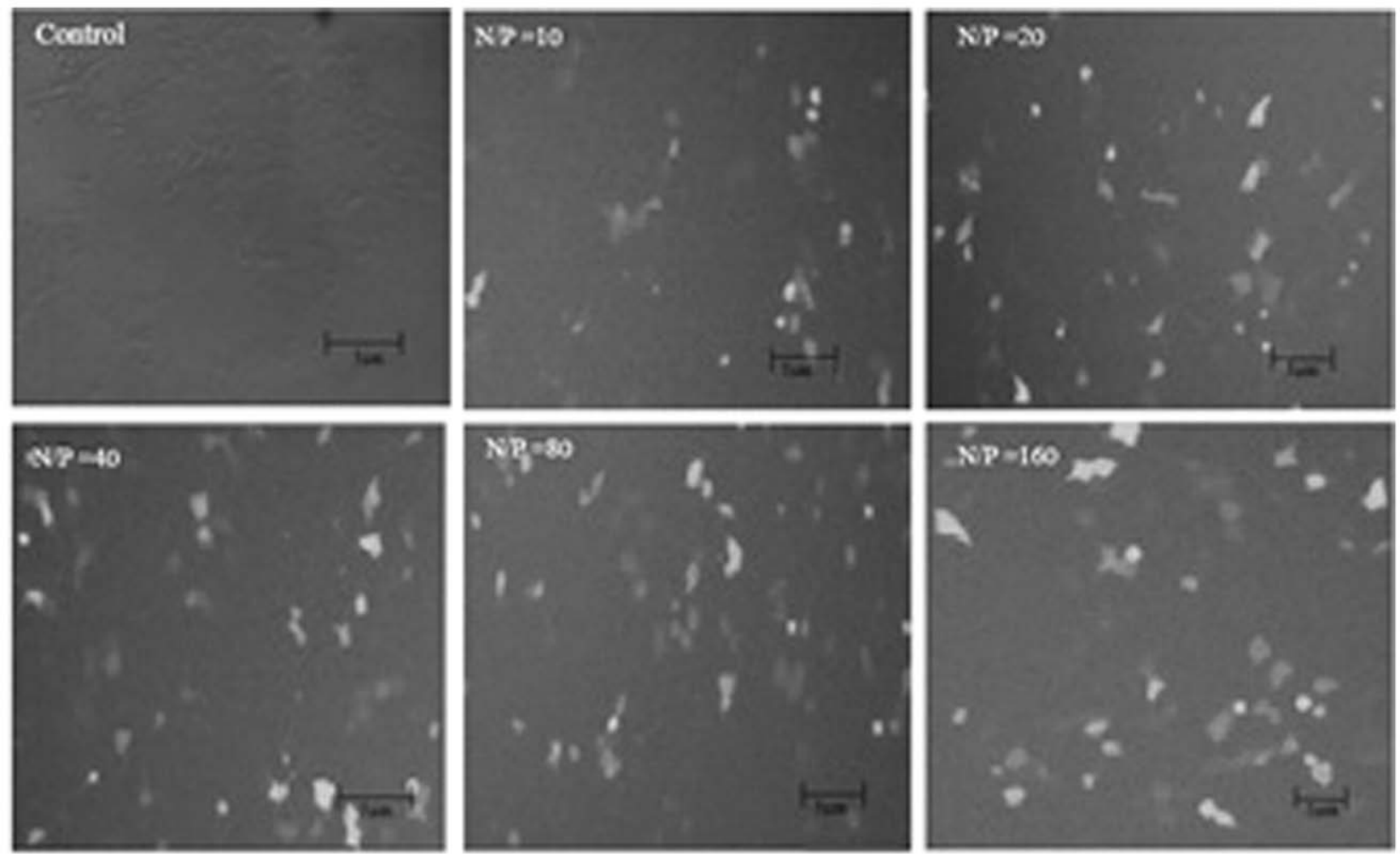

- Fig. 7 GFP fluorescence imaging: $4 \mathrm{~T} 1$ cells were transfected by pEGFP-N1 after $48 \mathrm{~h}$ at different N/P ratios (Control, and: N/P=10, N/P=20, $\mathrm{N} / \mathrm{P}=40, \mathrm{~N} / \mathrm{P}=80$, and $\mathrm{N} / \mathrm{P}=160$ ). 

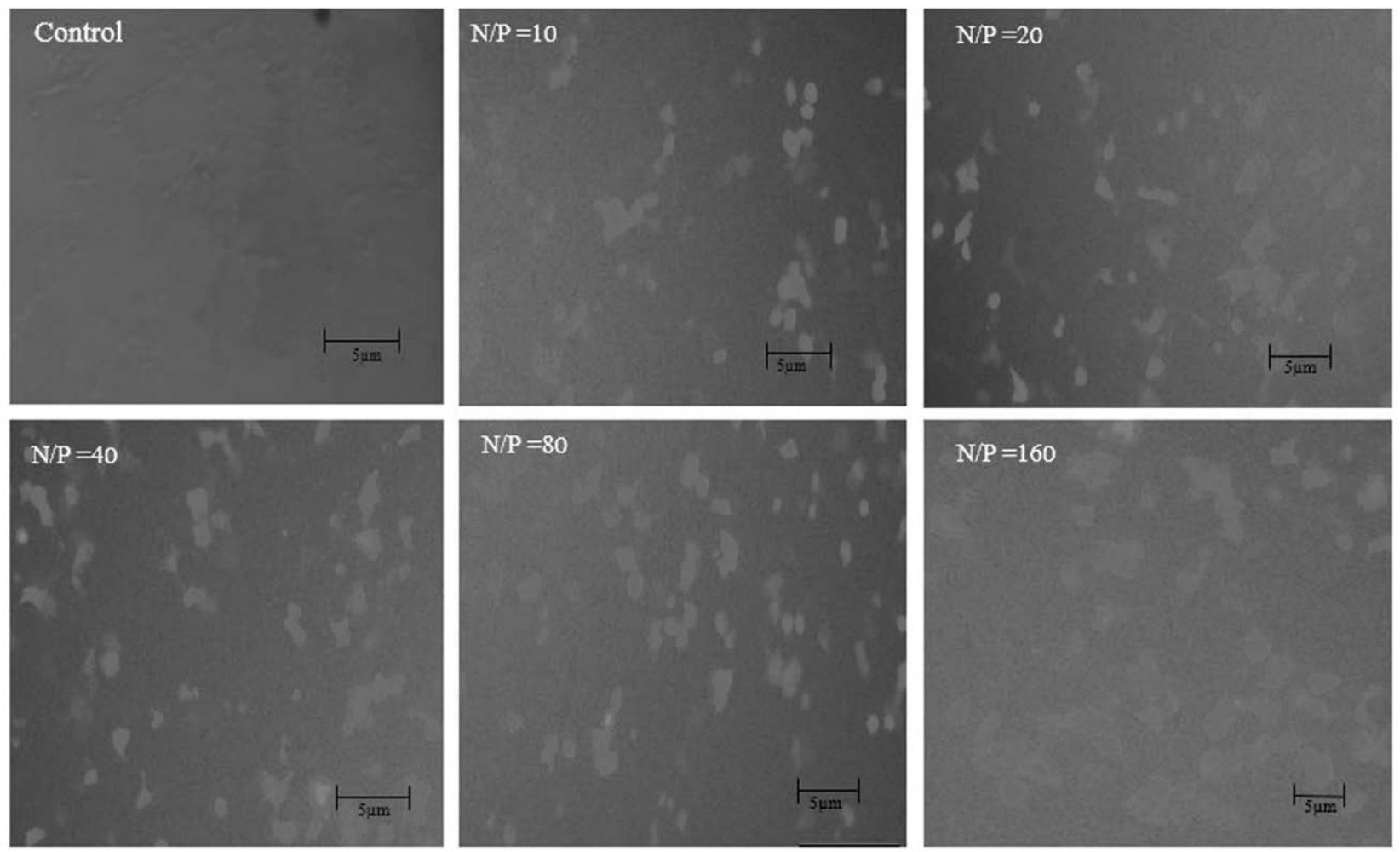

Fig. 8 Flowcytometry imaging: 4T1 cells were transfected by pEGFP-N1 after $48 \mathrm{~h}$ at different N/P ratios: a Control, b N/P=10 ( $\%$ transfection; 7.9), c N/P= 20 (\%transfect; 17.6), d N/P=40 (\%transfect; 25.9), e N/P= 80 (\%transfect; 35.2), f N/P = 160, (\%transfect; 45.8)

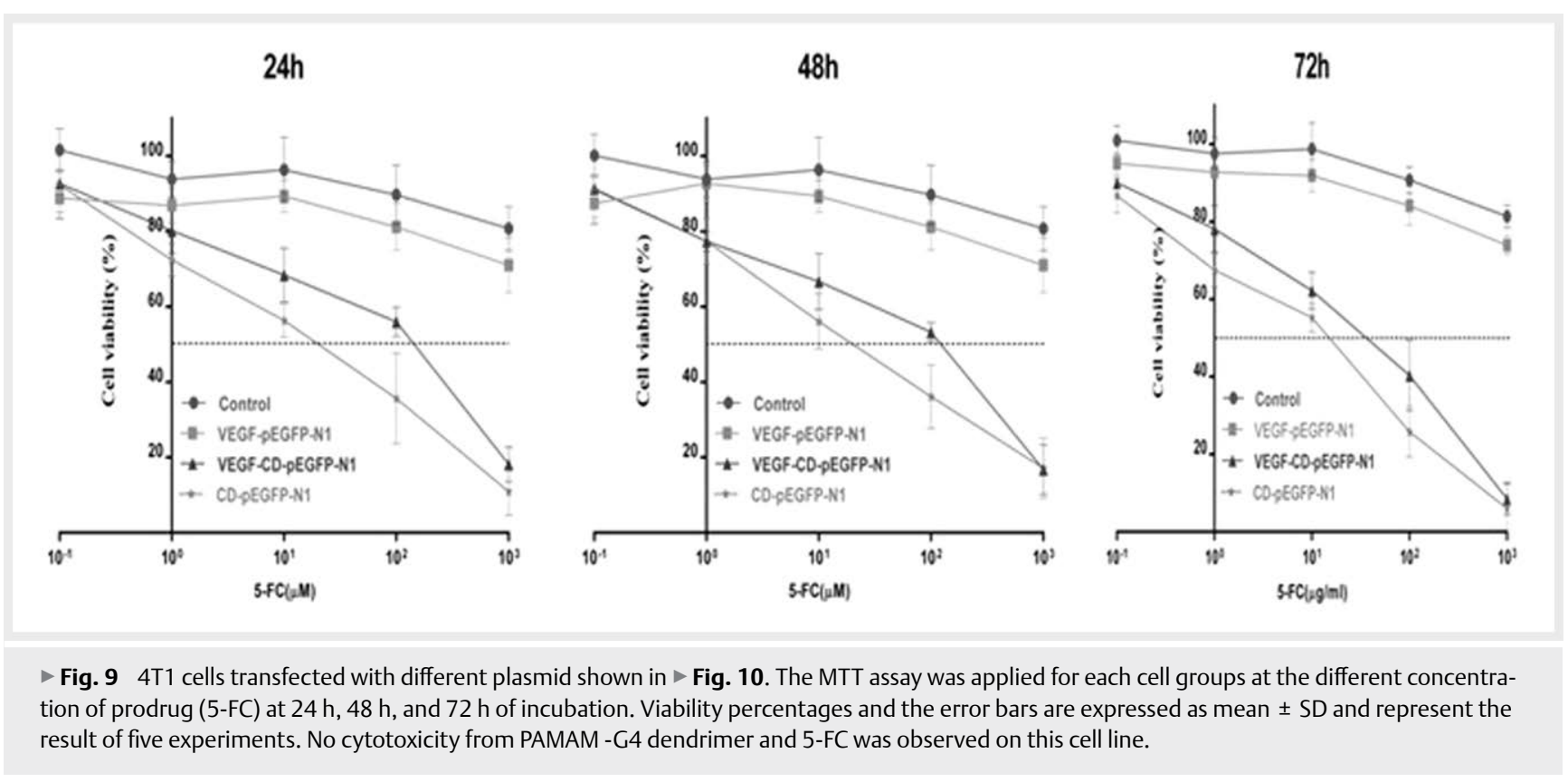

\section{Discussion}

The purpose of this study was evaluation of the effectiveness of VEGF promoter and bystander effect on the efficiency of the $\mathrm{CD} / 5$ FC enzyme/prodrug system using a dendriplex-based non-viral gene delivery system. Non-viral gene delivery systems are highly regarded for their many advantages compared to viral gene delivery systems [45]. However, their low efficiency in cell transfection has restricted their applications in clinic. Therefore, researchers are 

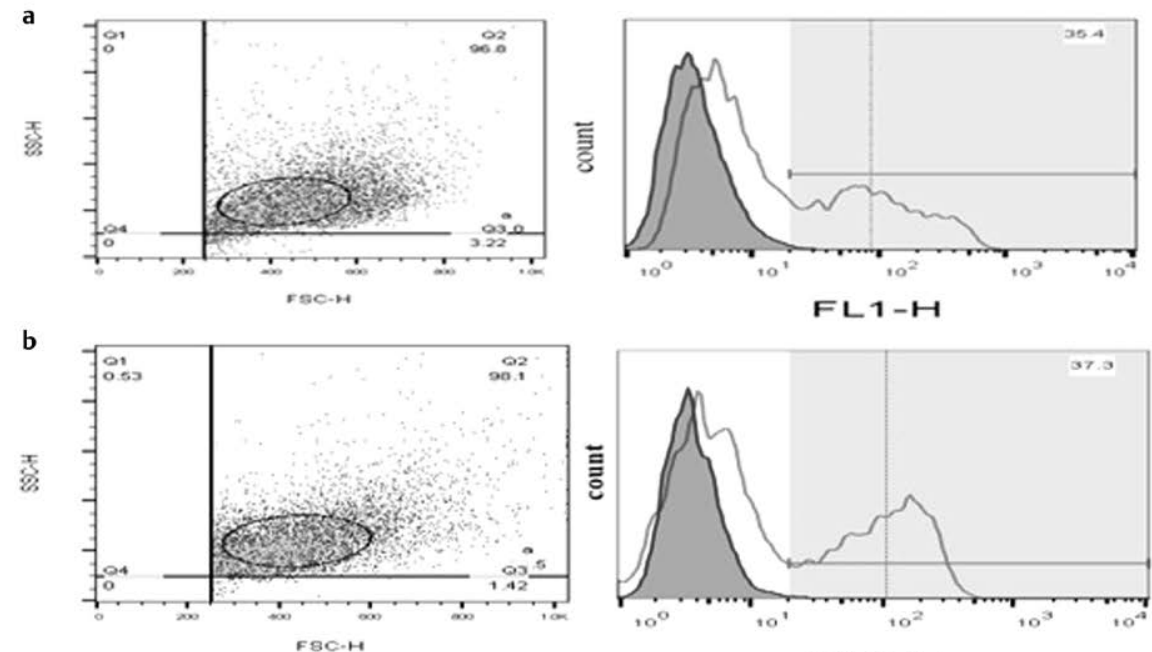

c

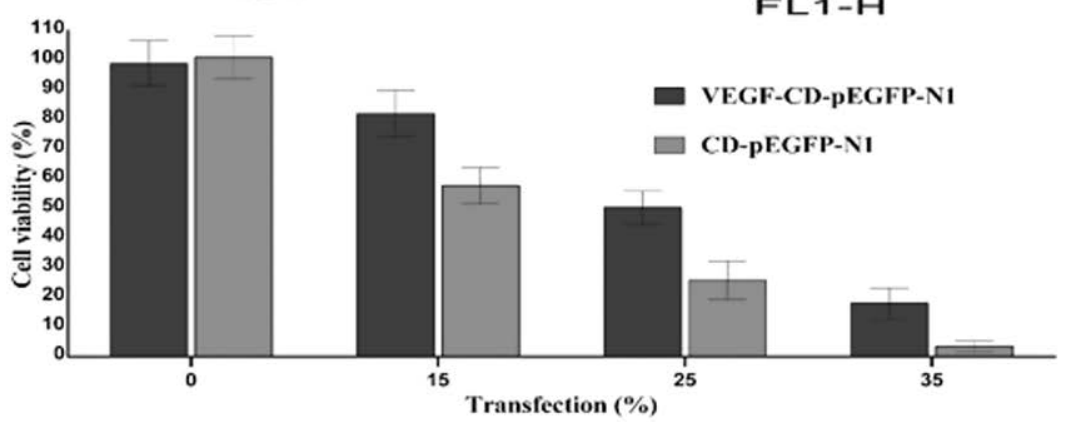

Fig. 10 a, b Flowcytometry analysis of transfected cells by VEGF-CD-pEGFP-N1 and CD- pEGFP-N1 respectively c The cell viability versus normalized cell transfection \% diagram, the blue and red columns represent the cells treated by the VEGF-CD-pEGFP-N1 and pEGFP-N1- CD plasmids, respectively.

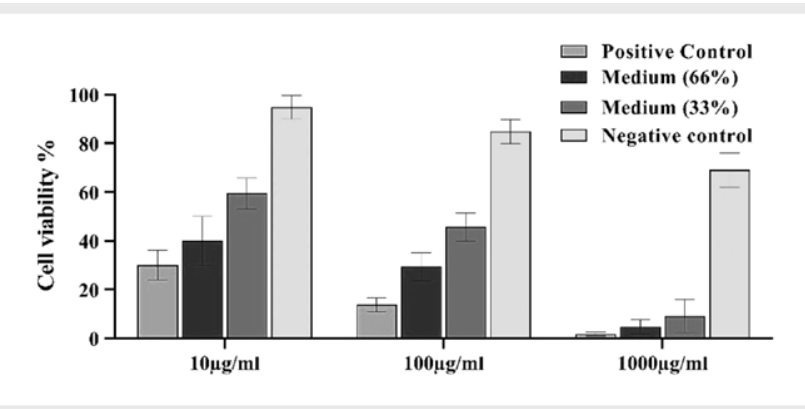

Fig. 11 Cell supernatant of transfected cells causes cytotoxicity on non-transfected cells after addition of prodrug.

looking for a way to compensate this shortcoming of non-viral systems and replace non-viral systems with today's high-risk viral systems. One potential therapeutic strategy for cancer treatment is the technique of inserting suicide genes that activate prodrugs to produce cytotoxicity in tumor cells. Suicide gene therapy, utilizing the cytosine deaminase/5-fluorocytosine ( $\mathrm{CD} / 5-\mathrm{FC})$ system, is an efficient procedure for targeted therapy in cancer research with promising results in previously reported studies $[46,47]$. It is based on the introduction of a viral or bacterial gene (and or fungal gene)

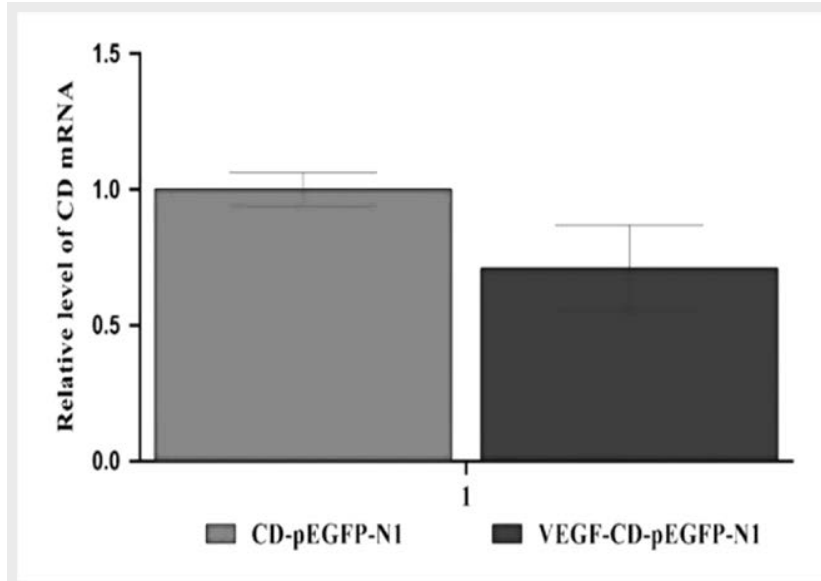

- Fig. 12 Expression of $C D$ gene (mRNA). The high-level of CD expression was detected in transfected cells by CD-pEGFP-N1. $\beta$-actin was used to normalize the experiment.

that encodes a metabolic enzyme into target cells, which allows the conversion of a non-toxic compound into a lethal drug, causing the death of target cells. The 'bystander effect' is a phenomenon whereby the transfection or transduction of a small fraction of 
target cells with the suicide gene may result in widespread target cell death, including the non-transfected cells [48]. Among many GDEPT, the most frequently used suicide gene therapy for clinical trials approved by the FDA, are two major systems as: the CD/5-FC system along or with the (HSV-TK)/GCV system [46]. Cytosine Deaminase, which normally catalyzes the deamination of cytosine to uracil during RNA biosynthesis, is found in many bacteria and fungi but not in mammalian cells [49]. However, the drug has no or low toxicity for normal mammalian cells. 5-FC is an antifungal drug compound that is non-cytotoxic but is transformed into 5-FU following deamination by the CD gene, which is more cytotoxic and may act to inhibit cellular proliferation [48]. Because of these many advantages of the $\mathrm{CD} / 5$-FC system and having a suitable bystander effect, we decided to deliver this system with a dendrimer-based non-viral gene delivery system. We can have a comparison between the high-risk viral method at literature and the low-risk non-viral method [50], and we hoped that the low efficiency of the non-viral gene delivery system would be offset by the bystander effect.

The plasmid (pEGFPN1) contains of the cytosine deaminase (CDase) suicide gene, under the VEGF promoter (VEGF-CD-pEGFPN1), was used to transfect 4T1 cells with the G4-PAMAM dendriplex. The highest efficiency after optimization of the most factors for our non-viral system was between $40-50 \%$, and we investigated if cells transfection was $50 \%$, it is enough to kill all of the transfected cells and nontransfected cells? For this purpose, we organize the bystander effect test [43] performed on on transfected cells, with non-viral gene delivery systems. The results showed that in $35 \%$ transfection, cells transfected with plasmid VEGF-CD-pEGFPN1 and CD-pEGFP-N1 inhibited the growth of cancer cells by 80 and $90 \%$, respectively.

Another aim of this project was to confirm the expression of CD gene by transfected cells. For this purpose, three methods were used. First, because we know that both the CD and GFP genes are under the same promoter, the expression of GFP will also express the expression of the CD gene in a way that the expression of GFP gene was quantitatively and qualitatively confirmed. Second, unlike transfected cells with CD-plasmids, cell transfected with $\mathrm{CD}^{+}$plasmids showed toxicity at a certain concentration of prodrug, which could be due to the function of $C D$ enzyme and conversion of prodrug to a more toxic drug (5-fluorouracil). Third, the expression of the $C D$ gene at the transcriptional level was confirmed by real-time PCR method the presence of CD gene mRNA in total RNA of transfected cells with $\mathrm{CD}^{+}$plasmids.

In this study, we created a plasmid controlled by a cancer specific promoter (VEGF). The VEGF promoter was obtained from 4T1 cell lines and inserted into the pEGFP-N1 expression plasmid. Another plasmid was constructed under the control of the CMV promoter, as a standard promoter [51], to make an appropriate comparison between the function of the VEGF promoter and the standard CMV promoter. The results of bystander effect test and real-time PCR showed that the VEGF promoter function can act close to the CMV promoter of the standard PEGFP-N1 plasmid. The mRNA content of the CD gene produced by VEGF-CD - PEGFP-N1 in the $4 \mathrm{~T} 1$ cells was $70 \%$ of mRNA content of the CD gene under control of CMV promoter (CD - pEGFP-N1) in the $4 \mathrm{~T} 1$ cells.
In summary, it demonstrated that the G4-PAMAM denderimermediated suicide gene $\mathrm{CD} / 5-\mathrm{FC}$ system can inhibite $4 \mathrm{~T} 1$ cell proliferation, and exerted a 'bystander effect'. This approach may be providing a novel framework for suicide gene therapy to treat breast cancer and or other kinds of cancers (especially gliomas). 4T1-specific delivery by G4-PAMAM-denderimer-mediated suicide $C D$ gene with the addition of specific promoters upstream of the suicide gene may be provide a therapeutic potential for treatment of breast cancer in future.

\section{Conclusion}

In this study we have attempted to improve the antitumor efficacy in 4T1 metastasizing breast carcinoma mice by using expressional shuttle vector to transfer cytosine deaminase gene under control of VEGF promoter in combination with non-viral PAMAM dendrimer, followed by 5-FC treatment. The results show inducing apoptosis in 4T1-trasfected cell and a marked inhibition of tumor cell growth, suggesting CD gene transfer driven by VEGF promoter plus a safe non-viral vector followed by 5-FC treatment, may be an alternative therapeutic approach for the breast cancer treatment. Hence; Future studies in animals and clinical trials remain to follow the in vivo safety and efficiency of this therapeutic platform.

\section{Authors' Contributions}

M. E. and A.A. contributed to methodology, conceptualization, software, and writing of original draft; T. S contributed supervision; A.S. and A.B contributed project administration, supervision, review, and editing.

\section{Informed Consent}

All authors have read the manuscript and approved it for submission to your journal. All authors have agreed to authorship and order of authorship for this manuscript. Additionally, all authors have the appropriate permissions and rights to the reported data. Authors declare that they have no competing interests.

\section{Acknowledgements}

The present study was supported by Cancer Gene Therapy Research Canter, Zanjan University of Medical Sciences, Zanjan, Iran (Grant NO. A-12-848-15). We would like to thank Dr. Behzad Baradaran for providing the G4-PAMAM.

\section{Funding}

A-12-848-15; provided by Cancer Gene Therapy Research Center, Zanjan University of Medical Sciences, Zanjan, Iran.

\section{Conflict of Interest}

There is no conflict of interest. 


\section{References}

[1] Duarte $S$ et al. Suicide gene therapy in cancer: where do we stand now? Cancer letters 2012; 324: p 160-170

[2] Karantza V. Keratins in health and cancer: more than mere epithelial cell markers. Oncogene 2011; 30: p 127-138

[3] Malecki M. Frontiers in suicide gene therapy of cancer. Journal of genetic syndrome \& gene therapy 2012; 2012

[4] Ruegg C, Mutter N. Anti-angiogenic therapies in cancer: achievements and open questions. Bulletin du cancer 2007; 94: p 753-762

[5] Blattman JN, Greenberg PD. Cancer immunotherapy: a treatment for the masses. Science 2004; 305: p 200-205

[6] Noguchi T et al. miRNA-503 promotes tumor progression and is associated with early recurrence and poor prognosis in human colorectal cancer. Oncology 2016; 90: p 221-231

[7] Herr R, Brummer T. BRAF inhibitors in colorectal cancer: toward a differentiation therapy? Molecular \& cellular oncology 2015; 2: p e1002709

[8] Weber WA, Morris M]. Molecular imaging and targeted radionuclide therapy of prostate cancer. Journal of Nuclear Medicine 2016; 57: p $35-5 S$

[9] Lv Q et al. Molecular mechanisms and translational therapies for human epidermal receptor 2 positive breast cancer. International journal of molecular sciences 2016; 17: p 2095

[10] González-Cao M et al. Targeting PD-1/PD-L1 in lung cancer: current perspectives. Lung Cancer 2015; 6: p 55

[11] Cheng $Y$ et al. Design of biocompatible dendrimers for cancer diagnosis and therapy: current status and future perspectives. Chemical Society Reviews 2011; 40: p 2673-2703

[12] Mintzer MA, Grinstaff MW. Biomedical applications of dendrimers: a tutorial. Chemical Society Reviews 2011; 40: p 173-190

[13] Morgan RA. Live and let die: a new suicide gene therapy moves to the clinic. Molecular Therapy 2012; 20: p 11-13

[14] Mehier-Humbert S, Guy RH. Physical methods for gene transfer: improving the kinetics of gene delivery into cells. Advanced drug delivery reviews 2005; 57: p 733-753

[15] Ramamoorth M, Narvekar A. Non viral vectors in gene therapy-an overview. Journal of clinical and diagnostic research: JCDR 2015; 9: $\mathrm{p}$ GE01

[16] Wirth T, Ylä-Herttuala S. Gene therapy used in cancer treatment. Biomedicines 2014; 2: p 149-162

[17] Hermiston T. Gene delivery from replication-selective viruses: arming guided missiles in the war against cancer. The Journal of clinical investigation 2000; 105: p 1169-1172

[18] Gopinath P, Ghosh SS. Monitoring green fluorescent protein for functional delivery of $\mathrm{E}$. coli cytosine deaminase suicide gene and the effect of curcumin in vitro. Gene Ther Mol Biol 2007; 11: p 219-228

[19] Springer C], Niculescu-Duvaz I. Patent property of suicide gene therapy involving prodrugs 1996-1999. Expert Opinion on Therapeutic Patents 1999; 9: p 1381-1388

[20] Akbulut $\mathrm{H}$ et al. Cytotoxic effect of replication-competent adenoviral vectors carrying L-plastin promoter regulated $\mathrm{E} 1 \mathrm{~A}$ and cytosine deaminase genes in cancers of the breast, ovary and colon. Cancer Gene Therapy 2003; 10: p 388-395

[21] Ireton GC, Black ME, Stoddard BL. The $1.14 \AA$ A crystal structure of yeast cytosine deaminase: evolution of nucleotide salvage enzymes and implications for genetic chemotherapy. Structure 2003; 11: p 961-972

[22] Liu Y et al. Engineering conditionally replication-competent adenoviral vectors carrying the cytosine deaminase gene increases the infectivity and therapeutic effect for breast cancer gene therapy. Cancer gene therapy 2006; 13: p 346-356
[23] Freeman SM et al. The "bystander effect": tumor regression when a fraction of the tumor mass is genetically modified. Cancer research 1993; 53: p 5274-5283

[24] Mullen CA, Kilstrup M, Blaese RM. Transfer of the bacterial gene for cytosine deaminase to mammalian cells confers lethal sensitivity to 5-fluorocytosine: a negative selection system. Proceedings of the National Academy of Sciences 1992; 89: p 33-37

[25] Fischer $U$ et al. Mechanisms of thymidine kinase/ganciclovir and cytosine deaminase/5-fluorocytosine suicide gene therapy-induced cell death in glioma cells. Oncogene 2005; 24: p 1231-1243

[26] Negroni L et al. Treatment of colon cancer cells using the cytosine deaminase/5-fluorocytosine suicide system induces apoptosis, modulation of the proteome, and $\mathrm{Hsp} 90 \mathrm{\beta}$ phosphorylation. Molecular cancer therapeutics 2007; 6: p 2747-2756

[27] Kanai F et al. Adenovirus-mediated transduction of Escherichia coli uracil phosphoribosyltransferase gene sensitizes cancer cells to low concentrations of 5-fluorouracil. Cancer research 1998; 58: p 1946-1951

[28] Cramer F et al. Insertion of a nuclear factor kappa B DNA nucleartargeting sequence potentiates suicide gene therapy efficacy in lung cancer cell lines. Cancer gene therapy 2012; 19: p 675-683

[29] Ostertag $D$ et al. Brain tumor eradication and prolonged survival from intratumoral conversion of 5 -fluorocytosine to 5 -fluorouracil using a nonlytic retroviral replicating vector. Neuro-oncology 2011; $14: p$ 145-159

[30] Kaliberov SA, Buchsbaum D]. Cancer treatment with gene therapy and radiation therapy. Advances in cancer research 2012; 115: p 221-263

[31] Sterman DH et al. A phase I trial of repeated intrapleural adenoviralmediated interferon- $\beta$ gene transfer for mesothelioma and metastatic pleural effusions. Molecular Therapy 2010; 18: p 852-860

[32] Zarogoulidis P et al. Management of malignant pleural effusion by suicide gene therapy in advanced stage lung cancer: a case series and literature review. Cancer gene therapy 2012; 19: p 593-600

[33] Dorer DE, Nettelbeck DM. Targeting cancer by transcriptional contro in cancer gene therapy and viral oncolysis. Advanced drug delivery reviews 2009; 61: p 554-571

[34] Karjoo Diarkhan Z. Customization and optimization of a histone h2a-based vector for targeted gene transfer to cancer cells. 2015; Rutgers University-Graduate School-New Brunswick.

[35] Kurayoshi K et al. Cancer cell specific cytotoxic gene expression mediated by ARF tumor suppressor promoter constructs. Biochemical and biophysical research communications 2014; 450: p 240-246

[36] Kia $A$ et al. Dual systemic tumor targeting with ligand-directed phage and Grp78 promoter induces tumor regression. Molecular cancer therapeutics 2012; 11: p 2566-2577

[37] Zhu ZB et al. Transcriptional targeting of adenoviral vector through the CXCR4 tumor-specific promoter. Gene therapy 2004; 11: p 645-648

[38] Chen X, Godbey W. The potential of the human osteopontin promoter and single-nucleotide polymorphisms for targeted cancer gene therapy. Current gene therapy 2015; 15: p 82-92

[39] Nemunaitis J et al. A phase I study of telomerase-specific replication competent oncolytic adenovirus (telomelysin) for various solid tumors. Molecular Therapy 2010; 18: p 429-434

[40] Konecny GE et al. Association between HER-2/neu and vascular endothelial growth factor expression predicts clinical outcome in primary breast cancer patients. Clinical cancer research 2004; 10: $\mathrm{p}$ 1706-1716

[41] Abbaspour A, Esmaeilzadeh A, Sharafi A. Suicide gene therapy-mediated purine nucleoside phosphorylase/fludarabine system for in vitro breast cancer model with emphasis on evaluation of vascular endothelial growth factor promoter efficacy. 3 Biotech 2021; 11: p $1-14$ 
[42] Lappalainen $\mathrm{K}$ et al. Comparison of cell proliferation and toxicity assays using two cationic liposomes. Pharmaceutical research 1994; 11: p 1127-1131

[43] Zhang B et al. An ultrasonic nanobubble-mediated PNP/fludarabine suicide gene system: A new approach for the treatment of hepatocellular carcinoma. PloS one 2018; 13: p e0196686

[44] Ichikawa T et al. In vivo efficacy and toxicity of 5-fluorocytosine/ cytosine deaminase gene therapy for malignant gliomas mediated by adenovirus. Cancer gene therapy 2000; 7: p 74-82

[45] Al-Dosari MS, Gao X. Nonviral gene delivery: principle, limitations, and recent progress. The AAPS journal 2009; 11: p 671-681

[46] Karjoo Z, Chen X, Hatefi A. Progress and problems with the use of suicide genes for targeted cancer therapy. Advanced drug delivery reviews 2016; 99: p 113-128
[47] Malekshah OM et al. Enzyme/prodrug systems for cancer gene therapy. Current pharmacology reports 2016; 2: p 299-308

[48] Chaszczewska-Markowska M et al. Liposomal formulation of 5 -fluorocytosine in suicide gene therapy with cytosine deaminase-for colorectal cancer. Cancer letters 2008; 262: p 164-172

[49] Kilstrup M et al. Genetic evidence for a repressor of synthesis of cytosine deaminase and purine biosynthesis enzymes in Escherichia coli. Journal of bacteriology 1989; 171: p 2124-2127

[50] Mandal S, Tiwari PK. Gene Therapy and Gene Editing for Cancer Therapeutics, in Handbook of Research on Advancements in Cancer Therapeutics. 2021; IGI Global p 116-204

[51] Zhao $Y$ et al. Gemcitabine resistance in triple-negative breast cancer cells can be reverted by Drosophila melanogaster deoxyribonucleoside kinase in the nucleus or cytosol. Oncology letters 2020; 20: p 1-1 